\title{
Vivências de mulheres sobre o parto
}

\author{
Carolina Lemes Valadão (D) * Renata Fabiana Pegoraro \\ Universidade Federal de Uberlândia, Uberlândia, $M G$, Brasil
}

Resumo

No Brasil, a medicalização do parto é apontada por diferentes autores e confirmada pelas estatísticas a respeito. Diante da importância deste tema, o presente trabalho teve por objetivo compreender a vivência do parto segundo relato de mulheres. Foram entrevistadas oito mulheres, de 23 a 32 anos, que tiveram pelo menos um filho pela rede pública de saúde por meio de roteiro semiestruturado. Os resultados apontaram a preferência pelo tipo de parto, o momento de ir para o hospital, a presença do acompanhante, o contato com o bebê no pós-parto, a falta de protagonismo feminino, o ambiente pouco acolhedor e a percepção sobre o atendimento. Foram apontados aspectos urgentes a serem revistos na assistência ao parto, como a falta de vínculo entre a mulher e a equipe de saúde e restrições em relação ao acompanhante, o que distancia a prática do que é definido como prioridade pela Política Nacional de Humanização.

Palavras-chave: parto; mulher; humanização da assistência.

\section{Experiences of women on childbirth}

\begin{abstract}
In Brazil, many authors study the childbirth medicalization and the statics confirm it. This research aimed at learning about the childbirth experience by women attending in the public health system. Semi-structured interviews were conducted with eight womans, age 23-32 years, who gave birth in public health system was interviewed with semi-estructured script. The results showed preference of childbirth way, how the woman decided that was the moment to go to the hospital, the partner's presence, lack of empowerment, professional assistance and the first contact with the newborn. The woman showed in their histories that something must to change immediately in the childbirth experience, like: the lack of link between the woman and the health team and restrictions about the partner's presence. The reality is very different of the public policy.
\end{abstract}

Keywords: childbirth; woman; humanization of assistance.

\section{Introdução}

O tema deste artigo é a vivência de mulheres sobre a experiência do parto na rede pública de saúde na região do triângulo mineiro. Este estudo se justifica pela compreensão de que ouvir os relatos das vivências de mulheres sobre a assistência ao parto pode ajudar a refletir e problematizar sobre as práticas que vêm sendo adotadas atualmente no Brasil.

Em 2011 foi publicada a "Política Nacional de Atenção Integral à Saúde da Mulher - Princípios e Diretrizes" (BRASIL, 2011). Este documento busca consolidar os avanços dos direitos sexuais e reprodutivos das mulheres e efetivar a melhoria da atenção obstétrica ao aborto inseguro, no planejamento familiar e no combate à violência doméstica e sexual. Com essa política, o Ministério da Saúde (BRASIL, 2011) propõe uma construção conjunta de respeito, empoderamento e autonomia das usuárias do Sistema Único de Saúde (SUS), tendo em vista que, no Brasil, o histórico das mulheres na busca de um atendimento em saúde expressa discriminações e violações dos direitos básicos.

A humanização na atenção à saúde da mulher implica a promoção, o reconhecimento e o respeito aos direitos humanos (BRASIL, 2014), incluindo os eventos da gestação, parto e nascimento, de forma a colocar a mulher como protagonista destes eventos. A gestação e o parto não são apenas eventos biológicos, mas também sociais,

\footnotetext{
^Endereço para correspondência: Universidade Federal de Uberlândia, Instituto de Psicologia. Avenida Pará, 1720 - Sala 47, Bloco 2 - C. Umuarama - Uberlândia, MG - Brasil. CEP: 38405320.E-mails: krol.valadao@gmail.com, rfpegoraro@yahoo.com.br

Os dados completos das autoras encontram-se ao final do artigo.
}

uma vez que envolvem família e comunidade, cuja protagonista deve ser a mulher. Nesse cenário, os profissionais de saúde possuem um papel importante, porém como coadjuvantes: a equipe de saúde deve estar ao lado da mulher para prestar apoio, ajudar a minimizar a dor, orientar e saber reconhecer momentos críticos (BRASIL, 2008).

Na prática, o que se vê no Brasil é que o parto tornou-se um evento médico, biológico, no qual o patológico é valorizado. A pesquisa "Nascer no Brasil", feita pela Fundação Oswaldo Cruz (LEAL; GAMA, 2014), mostrou que o percentual de partos cirúrgicos atingiu a margem de $52 \%$, enquanto que o indicado pela Organização Mundial da Saúde (OMS) é de 15\%. Na rede particular de saúde, esse índice chega a $88 \%$. No município de Uberlândia (MG), onde o presente estudo foi realizado, o número de cesarianas registradas no ano de 2015 foi de 3105 contra 2450 partos naturais ( $55 \%$ de cesáreas), considerando-se a rede pública e a privada (ALEIXO, 2017).

$\mathrm{Na}$ pesquisa citada (LEAL; GAMA, 2014), observou-se que, dentre os partos vaginais, apenas 5\% são naturais, sem intervenções médicas; $36,4 \%$ das mulheres receberam ocitocina sintética para acelerar o trabalho de parto, 53,5\% sofreram episiotomia (corte feito na região do períneo para ampliar o canal de parto) e $91,7 \%$ das mulheres foram obrigadas a ficar na posição de litotomia (deitadas com as pernas para cima). O alto grau de intervenção nos partos mostra que a prática dos médicos brasileiros está em descompasso com as recomendações internacionais e com as recomendações do SUS (LEAL; GAMA, 2014). 
Os dados apresentados apontam para uma atenção à mulher no trabalho de parto e no parto marcado pela intensa medicalização, por intervenções desnecessárias e pelo número abusivo de cesarianas (LEAL; GAMA, 2014). Além disso, muitas mulheres não conseguem ter um acompanhante, mesmo tendo esse direito assegurado pela Lei 11.108 (BRASIL, 2005).

Essa profunda distorção da forma de nascer no Brasil pode ter muitas razões, uma delas, a medicalização do corpo feminino. Não se pode negar que os avanços na área da obstetrícia e a cesárea foram importantes instrumentos para a redução da mortalidade materna, porém, quando não indicada, a cesárea oferece mais riscos às mulheres e crianças do que um parto normal, como infecções e hemorragias. Outros motivos que podem justificar o uso abusivo das cesarianas são: maior pagamento dos honorários profissionais no caso de parto cirúrgico, a economia de tempo e a realização clandestina da laqueadura tubária no momento do parto (BRASIL, 2008).

Historicamente, o parto era considerado um evento natural e feminino, de caráter íntimo e privado. Com os avanços da medicina e particularmente da obstetrícia, o parto começou a se tornar um evento médico, deixando de ser íntimo para ser público, com a entrada de novos atores sociais (BRASIL, 2008; WEIDLE et al., 2014).

Com a institucionalização do parto, o nascimento tornou-se algo distante e desconhecido para as mulheres, já que elas não detêm mais o protagonismo do parto. São reféns dos profissionais de saúde, o que as leva a questionar a segurança do parto normal frente ao cirúrgico, que se mostra mais limpo, rápido e científico. Instituiu-se uma cultura a favor da cesárea. Como consequência, os obstetras não são capacitados para o atendimento a um parto normal, e, na relação médico x paciente, as mulheres têm dificuldades em participar das decisões sobre o tipo de parto e não se sentem capacitadas a fazer valer seus direitos diante das "questões técnicas" levantadas pelo médico (BRASIL, 2008).

É imprescindível para a humanização do parto a preparação da mulher durante o pré-natal. Além de aspectos técnicos, o preparo para o parto envolve o acolhimento da mulher e sua família no serviço de saúde e o desenvolvimento de medidas que ofereçam a possibilidade de a mulher vivenciar o trabalho de parto e o parto como eventos fisiológicos, fazendo-a protagonista no processo (BRASIL, 2008).

Não prestar a devida atenção à mulher em trabalho de parto pode resultar em violência obstétrica. Essa violência se expressa na negligência à mulher, discriminação social, violência verbal (tratamento grosseiro, humilhações, ameaças, gritos, entre outros), violência física (uso indevido de intervenções médicas e procedimentos desnecessários) e até o abuso sexual (AGUIAR; D'OLIVEIRA, 2011). Muitos autores já procuraram entender a vivência de parto da perspectiva das mulheres (GOMES; NATIONS; LUZ, 2008; DOMINGUES; SANTOS; LEAL, 2004; OLIVEIRA et al., 2010; OLIVEIRA et al., 2002; AGUIAR; D'OLIVEIRA, 2011). Os discursos das mulheres ouvidas nos referidos artigos confirmam que a prática médica anda em descompasso com as recomendações do Ministério da Saúde, e muitas reconheceram ter sofrido violência no momento do parto. A distância entre as recomendações presentes na legislação e as práticas médicas se reflete na ausência de ações para o conforto e bem-estar da mulher em trabalho de parto. Muitos procedimentos de rotina estão sendo questionados. A medicina baseada em evidências mostra que vários deles são desnecessários e colocam a saúde da mulher em risco; outros são claramente danosos e devem ser prevenidos, tais como a episiotomia, aceleração do parto e cesárea eletiva (DINIZ; CHACHAM, 2002).

$\mathrm{Na}$ maternidade, o corpo da mulher é visto como objeto de controle e domínio da medicina. Essa 'objetificação' traz em si preconceitos ligados ao gênero e à banalização do sofrimento da parturiente (pensamento vigente que a mulher "merece" aquele sofrimento em compensação ao prazer sexual). Banalizar o sofrimento é banalizar também a violência institucional que acontece nas maternidades e na sociedade como um todo (AGUIAR; D'OLIVEIRA, 2011).

No Brasil, vivemos um modelo obstétrico intervencionista, em que o médico é figura central no momento do parto, e a mulher, por sua vez, torna-se objeto de ação, não detendo o controle sobre esse processo. A autonomia da mulher está diretamente ligada à informação que ela possui sobre evidências científicas para melhor conduta no momento do nascimento. Portanto, é fundamental que a parturiente seja bem orientada no momento do pré-natal, visando a maiores benefícios na assistência ao parto (OLIVEIRA et al., 2002)

Domingues, Santos e Leal (2004) realizaram um estudo que ouviu aproximadamente 250 mulheres e por meio do qual se verificou que apenas $23 \%$ das mulheres entrevistadas sentiam-se completamente informadas sobre o que aconteceria com elas e com o bebê no momento do parto. Apenas $17,7 \%$ das mulheres perceberam o pré-natal como um serviço informativo, e $44 \%$ das mulheres afirmaram que a principal fonte de informação era a mãe e outros familiares.

Segundo Oliveira et al. (2010), as mulheres optam pelo parto cirúrgico por medo de sentir dor, orientação de amigos e por medo da possibilidade de lesões em um parto vaginal. Muitas mulheres são submetidas a uma cesariana, mas desconhecem o real motivo de tal procedimento, e quando apresentam alguma justificativa, muitas não coincidem com a indicação médica. Oliveira et al. (2010) afirmam ainda que a cultura da cesárea é difundida como um parto rápido e sem dor, e sustenta a prática médica atual. Considera-se também que a cultura de submissão ao saber médico utiliza-se do medo das parturientes ante ao desconhecido para se realizar uma cesárea que pode ser feita em dia e horários marcados e receber remuneração mais elevada. Em relação ao parto vaginal, a maioria das mulheres vê como principal benefício a rápida recuperação pós-parto. 
Em face do que foi exposto anteriormente, apresentaram-se como problemas de pesquisa deste estudo: de que maneira as mulheres, cujos bebês nasceram em um serviço da rede pública de saúde, percebem o atendimento recebido? Como se deu a escolha do tipo de parto? Como a parturiente decidiu que era o momento de ir para o hospital? Como foi o contato com o bebê no pós-parto imediato?

A partir dos problemas de pesquisa mencionados, o objetivo deste trabalho foi compreender a vivência do parto na perspectiva de mulheres assistidas pela rede pública de saúde.

\section{Aspectos metodológicos}

Esta pesquisa foi desenvolvida a partir da perspectiva qualitativa por meio de entrevistas. Segundo Duarte (2004, p. 215), as entrevistas "são fundamentais quando se precisa/deseja mapear práticas, crenças, valores e sistemas classificatórios de universos sociais específicos, mais ou menos bem delimitados, em que os conflitos e contradições não estejam claramente explicitados". Seu emprego, em estudos qualitativos, permite ao pesquisador:

[...] fazer uma espécie de mergulho em profundidade, coletando indícios dos modos como cada um daqueles sujeitos percebe e significa sua realidade e levantando informações consistentes que lhe permitam descrever e compreender a lógica que preside as relações que se estabelecem no interior daquele grupo, o que, em geral, é mais difícil obter com outros instrumentos de coleta de dados (DUARTE, 2004, p. 215).

A partir do interesse em conhecer a vivência sobre o parto da rede SUS, foram convidadas para participar desta pesquisa mulheres maiores de 18 anos e que tiveram ao menos um parto realizado na rede pública de saúde. Foram critérios de inclusão ter tido gravidez de baixo risco e disponibilidade para ceder entrevista gravada em áudio. Foram considerados critérios de exclusão: gravidez de risco, histórico de transtorno mental grave e/ ou acompanhamento da mulher pelo programa de saúde mental da Secretaria Municipal de Saúde em um Centro de Atenção Psicossocial (CAPS).

As mulheres foram contactadas no período de janeiro a março de 2015, a partir de uma unidade básica de saúde localizada no município de Uberlândia, durante seu horário de funcionamento. A entrevistadora dirigiu-se à unidade de saúde, conforme horário combinado com o gestor do serviço, e abordou mulheres que aguardavam consultas na sala de espera do local. Foi feito um rapport inicial, em que a entrevistadora apresentou-se e perguntou sobre a possibilidade de transmitir informações sobre a pesquisa. Quando havia concordância, era feito um breve relato do estudo e, em caso positivo, agendada uma entrevista em data e horário mais convenientes para a participante. As entrevistas aconteceram nas casas das participantes, como forma de preservar sua identidade na unidade de saúde. $\mathrm{Na}$ data agendada, a entrevista foi gravada em aúdio.
O instrumento elaborado para coleta de dados foi um roteiro de entrevista semiestruturado, dividido em duas partes: (a) Dados de caracterização (idade; número e idade dos filhos; número de filhos que nasceram pela rede pública de saúde; se tinha companheiro; ocupação/profissão; religião; escolaridade; renda familiar e com quem residia) e (b) Questões norteadoras (possibilidade de escolha do tipo de parto; relato sobre a decisão do momento de ir para o hospital para o nascimento do bebê; como a mulher foi recebida pela equipe de saúde no hospital; percepções sobre o trabalho da equipe que a assistiu durante o parto; uso de métodos para alívio da dor; relato da experiência de contato com o bebê logo após o nascimento).

Este estudo faz parte de uma pesquisa mais ampla aprovada pelo Comitê de Ética em Pesquisa com Seres Humanos da Universidade Federal de Uberlândia (Parecer 922.584). Em todos os casos, as participantes assinaram um Termo de Consentimento Livre e Esclarecido (TCLE) antes do início da entrevista. O termo informa às participantes sobre os objetivos e procedimentos do estudo, bem como garante livre participação e anonimato. Para garantir o sigilo quanto à identidade, as participantes não serão identificadas, sendo designadas de acordo com a ordem das entrevistas (E1 para a primeira, E2 para a segunda, e assim por diante).

As entrevistas foram transcritas na íntegra e realizou-se análise de conteúdo (BARDIN, 1977). A análise de conteúdo é usada quando se quer ir além dos significados, uma busca de outras realidades através das mensagens. É possível dividir a análise de conteúdo em três momentos: (1) A "pré-análise", em que se organiza o material, formulam-se questões norteadoras e, no caso das entrevistas, efetua-se a transcrição; (2) A "exploração do material": nesta etapa os dados brutos (transcritos) são transformados de forma organizada e agrupada em unidades de análise, as quais permitem uma descrição das características pertinentes do conteúdo; (3) O "tratamento dos resultados": por fim, as falas já organizadas por temáticas são lidas repetidas vezes em busca de possíveis semelhanças entre temas diferentes, para comparação com a literatura da área (BARDIN, 1977).

\section{Resultados}

Foram entrevistadas oito mulheres cujos filhos nasceram na rede pública de saúde na cidade de Uberlândia. As mulheres tinham idade entre 23 e 32 anos, entre um e três filhos, viviam com um companheiro, e a renda familiar variava entre $\mathrm{R} \$ 1.000,00$ (mil reais) e $\mathrm{R} \$ 4.000,00$ (quatro mil reais). Duas delas eram donas de casa, e as demais exerciam atividade remunerada. Em relação à escolaridade, uma das entrevistadas possuía ensino fundamental incompleto, cinco possuíam ensino médio completo e apenas uma cursou ensino superior completo. Três entrevistadas disseram não ter preferência religiosa, duas eram católicas, duas evangélicas e uma declarou-se cristã. A Tabela 1 apresenta o perfil de cada entrevistada. 
Tabela 1 - Características das entrevistadas

\begin{tabular}{|c|c|c|c|c|c|c|c|}
\hline Entrevista & $\begin{array}{l}\text { Idade } \\
\text { (anos) }\end{array}$ & $\begin{array}{l}\text { Compa- } \\
\text { nheiro }\end{array}$ & Ocupação & Escolaridade & $\begin{array}{l}\text { Preferência } \\
\text { Religiosa }\end{array}$ & $\begin{array}{c}\text { Renda } \\
\text { Familiar } \\
\text { (R\$) }\end{array}$ & $\begin{array}{l}\mathrm{N}^{\circ} \mathrm{de} \\
\text { Filhos }\end{array}$ \\
\hline E01 & 27 & Sim & Dona de Casa & $\begin{array}{c}\text { Médio } \\
\text { Completo }\end{array}$ & Cristã & 1500,00 & 3 \\
\hline E02 & 27 & Sim & $\begin{array}{c}\text { Auxiliar } \\
\text { Administra- } \\
\text { tivo }\end{array}$ & $\begin{array}{c}\text { Médio } \\
\text { Completo }\end{array}$ & Católica & 1400,00 & 2 \\
\hline E03 & 26 & Sim & $\begin{array}{c}\text { Atendente de } \\
\text { Telemar- } \\
\text { keting }\end{array}$ & $\begin{array}{c}\text { Médio } \\
\text { Completo }\end{array}$ & Católica & 2500,00 & 1 \\
\hline E04 & 23 & Sim & $\begin{array}{l}\text { Atendente de } \\
\text { Telemar- } \\
\text { keting }\end{array}$ & $\begin{array}{c}\text { Médio } \\
\text { Completo }\end{array}$ & Nenhuma & 2300,00 & 1 \\
\hline E05 & 31 & Sim & $\begin{array}{l}\text { Supervisora } \\
\text { de Telemar- } \\
\text { keting }\end{array}$ & $\begin{array}{l}\text { Superior } \\
\text { Completo }\end{array}$ & Evangélica & 3200,00 & 2 \\
\hline E06 & 27 & Sim & Comerciante & Não Declarou & Nenhuma & 4000,00 & 2 \\
\hline E07 & 32 & Sim & Dona de Casa & $\begin{array}{c}\text { Médio } \\
\text { Completo }\end{array}$ & Nenhuma & 1000,00 & 2 \\
\hline E08 & 25 & Sim & Cabelereira & $\begin{array}{c}\text { Fundamental } \\
\text { Incompleto }\end{array}$ & Evangélica & 2500,00 & 1 \\
\hline
\end{tabular}

A partir da análise das entrevistas, foram formados blocos temáticos de sentidos, descritos a seguir.

\section{Direitos nem sempre garantidos: a preferência pelo tipo de parto, presença do acompanhante e contato inicial com o bebê}

Todas as entrevistadas afirmaram que durante o pré-natal os médicos informaram que no sistema público de saúde há preferência pelo parto normal, mas relatam que não foram informadas sobre os benefícios desse tipo de parto. Mesmo tendo essa preferência dentro do sistema público de saúde declarada pelos profissionais que as atenderam, as mulheres não tinham a garantia de que essa seria a via de parto, pois, segundo os médicos, havia vários fatores que poderiam influenciar a decisão, tais como: diferenças de postura da equipe que iria receber a mulher no hospital, ter sido realizada cesárea em parto anterior e ocorrência prévia de aborto. Essa incerteza em relação ao tipo de parto pode ser ilustrada pela fala do médico para E2: "Tudo era lá na frente: 'porque eu não sei se vou fazer seu parto', 'porque eu não sei se vou estar lá no hospital', 'porque depende o médico que você vai ter'... era sempre assim que eles falavam".
Das oito mulheres entrevistadas, cinco tinham preferência pelo parto normal (E01, E04, E05, E06 e E07), duas pela cesárea (E02 e E08) e uma disse ter receio dos dois tipos de parto e, portanto, não tinha uma preferência definida (E03). Os motivos que levaram à declaração de preferência pela cesárea foram: aborto anterior (E08) e má experiência da mãe com o parto normal (E02), situação que levava à entrevistada ao medo de ter a mesma experiência. As entrevistadas que tinham preferência pelo parto normal alegavam poder ter melhor recuperação (E01, E04 e E06) e medo da cirurgia (E05 e E07).

As mulheres que tinham preferência pela cesárea manifestaram esse desejo durante o pré-natal, mas foram informadas de que essa não seria a primeira opção, como exemplificado pela E02: "Eu não queria parto normal, mas ele falava que na rede pública não tinha jeito. Só iriam fazer a cesárea só se não tivesse jeito". A entrevistada com receio dos dois tipos de parto declarou que as informações recebidas durante o pré-natal não foram suficientes para que ela se sentisse segura para a escolha: "A orientação que eles dão é que o parto normal é sempre melhor [...] Só que não adianta. O medo continuava...”. (E03) 
A decisão sobre o momento de ir para o hospital para o nascimento do bebê foi tomada por iniciativa da mulher quando envolveu o rompimento da bolsa (E04, E05) e início das contrações (E01, E02, E06), e por decisão do médico nos casos de ter 40 semanas de gestação (e iniciar indução - E03) e condições clínicas (como pouco líquido aminiótico e hipertensão arterial - E07 e 08).

A presença do acompanhante no trabalho de parto, parto e pós-parto é um direito assegurado por lei para as mulheres, porém nem sempre acontece. A análise dos relatos apontou três situações diferentes. A primeira delas envolve mulheres que não puderam ter acompanhante, como o relato: "E eu podia ver minha mãe só no outro dia, no horário de visita. Eu falei: 'Minha mãe pode ficar comigo?'. Ela [enfermeira] disse: 'Não, você tem que ficar sozinha. Não pode'." (E01)

A segunda situação refere-se à possibilidade de ter acompanhante apenas do sexo feminino:

$O T$. [marido] não podia ficar, porque lá era sala de gestante, então às vezes as mulheres ficam peladas, o médico faz exame de toque... então o homem não podia ficar, só minha mãe. Ai o T. ficou lá fora no carro e eu fiquei com a minha mãe. [Pesquisadora: Você queria que o T. Estivesse?] "Eu queria o $T$.

[Pesquisadora: Você tentou pedir?]

Aham... Eles não deixaram... (E05)

E, por fim, outras mulheres afirmaram que puderam ter acompanhante à escolha:

O meu marido assistiu todo o parto, viu tudo, ele pôde ficar dentro da sala. Aliás, ele acompanhou desde o momento que eu estava no UAI, que ele foi pra lá [...] até o momento depois que [a filha] nasceu. Então, durante aquele tempo todo que eu fico em trabalho de parto que é em uma sala reservada, ele pôde ficar comigo. (E06)

As entrevistadas relataram ainda como foi o contato com o bebê logo após o parto. Foi possível identificar que o contato tem ligação direta com o tipo de parto, de forma que, quando o parto foi vaginal, o contato foi imediato: "Logo quando ela nasceu, [...] elas já limparam a secreção e já colocaram ela em mim, pertinho assim para eu sentir ela [sic]”. (E06) Quando o parto foi cirúrgico, o contato demorou mais para ocorrer: "J. [filho] nasceu de manhã e eu fui ver o J. era duas horas da tarde [...] duas horas da tarde que eu peguei o J., aí que ele foi mamar". (E01)

\section{Falta de protagonismo da mulher, ambiente pouco acolhedor e a atenção recebida}

As mulheres entrevistadas relataram que sua autonomia não foi respeitada no trabalho de parto e no parto. Os desejos não foram respeitados pela equipe de saúde, e elas demonstravam certa passividade diante da postura médica, sem questionar a postura do profissional: "Aí eles amarraram a mão da gente... Não entendo! Não entendo por que! Fiquei muito revoltada com isso!" [Pesquisadora: Você questionou?] "Não cheguei a questionar, não”. (E03)

Fractal, Rev. Psicol., v. 32 - n. 1, p. 91-98, 2020
Outro exemplo de falta de escuta à mulher refere-se à posição para o parto não ser a da preferência da mulher. A Entrevistada 04, no entanto, reafirma sua vontade:

Na hora que eu entrei lá pra sala de parto mesmo, que tinha que pôr as pernas para cima, eu falei para ele que não ia pôr. Ai até a J. [enfermeira] levantou as minhas pernas. Eu começava a tremer as pernas e tirava.

[Pesquisadora: Se você pudesse escolher a posição naquela hora, qual posição você escolheria?]

As pernas para baixo [risos]. Com as pernas para cima não dá, não. Só com as pernas para baixo dobrado para mim já estava ótimo.

[Pesquisadora: E você se sentiu obrigada a ficar naquela posição?]

Não... Quando ele falou isso, eu falei: 'Vou ficar com as pernas para cima, porque ela já está saindo e se eu ficar segurando...' Eu não me senti obrigada, não, eu me senti no dever.

Durante as entrevistas, as mulheres contaram como eram atendidas pelos profissionais de saúde, sendo destaque o ambiente nada acolhedor e condutas inadequadas para o momento do parto quando já estava no hospital:

Para mim, parecia um matadouro. [...] parecia filme de terror. Ele [médico] saia da porta, entrava na outra porta. Aí a mulher [outra parturiente] saia de lá, eles colocavam ela no quarto, vinha com a outra, deitava e punha lá, saía da outra porta, entrava na outra, a que estava lá saía, e punha a outra, ficava lá esperando... E aí me colocaram lá, mas eu sabia que a $S$. [filha] não estava pronta para nascer. Ela não estava... ela não tava! Porque quando me colocaram lá, estava contando piada, ele contando que ia pra fazenda, e isso eu nunca vou esquecer, e aí eles cantando lá uma música do Zezé de Camargo e Luciano... que raiva!.

Aspectos negativos quanto aos profissionais de enfermagem também foram relatados:

Acho que só tinha que melhorar as enfermeiras. Tem umas que faz é graça. Você vê que está de deboche para cima de você! Porque depois que você está ali, você está precisando delas. Elas estão ali, elas estão ganhando para fazer aquilo ali. A gente entende que não é fácil. Eu queria ver se fosse elas lá, machucando elas [sic]. Porque tem umas que machuca a gente... Ficava com deboche pra cima da gente. Elas não precisam dizer algumas coisas. Na hora a gente está sentindo dor, gente! Elas têm que entender isso. Agora elas virarem para você e falar: 'Olha eu sei que está doendo, mas a próxima é pior, não se preocupe!' [tom de desaprovação].

Há também relatos de condutas positivas como fala a Entrevistada 05 a respeito de um médico: "Esse médico toda vez que ele tinha que fazer o exame de toque, ele me pedia. 'Você me autoriza?'... muito educado. Bom mesmo!'”. A mesma entrevistada também avaliou a equipe como um todo:

Eu achei o hospital excelente, a equipe médica muito preparada. Eles são até exigentes, sabe?! Assim, eu percebo que eles se cobram para fazer um bom trabalho. Eu imagino que tem alguém por trás disso que cobra eles [sic]. Eles são bem preparados... eu gostei bastante. (E05) 


\section{Discussão}

A humanização do parto envolve, entre outros fatores, o respeito à autonomia e ao protagonismo femininos (AMORIM, 2012). Assim, ouvir relatos de mulheres acerca da vivência do parto é uma maneira de avaliar a qualidade e como se dá o atendimento nos serviços de saúde.

A maioria das mulheres entrevistadas tinha preferência por um parto vaginal no início da gestação. Observa-se que, mesmo com as diversas recomendações do Ministério da Saúde (BRASIL, 2014) acerca do parto, os profissionais de saúde que acompanharam as mulheres no serviço de pré-natal não puderam garantir qual a via do parto, tendo em vista que não era possível assegurar em que instituição ocorreria o nascimento da criança.

Os relatos apontaram que as gestantes entrevistadas só tomaram conhecimento sobre para qual maternidade seriam encaminhadas no momento do parto, o que contraria a lei n.11.634 (BRASIL, 2007), que determina que, durante o pré-natal, toda gestante tem o direito de se vincular à maternidade onde receberá atenção no âmbito do SUS. Neste sentido, se os hospitais da rede pública do município em que o estudo foi desenvolvido permitem que as gestantes conheçam o setor de maternidade ainda durante a gestação, não lhes garantem em qual deles o bebê nascerá.

No município em que a coleta foi realizada existem três opções para a puérpera atendida na rede pública de saúde: o hospital escola da Universidade Federal de Uberlândia, o Hospital Municipal vinculado à Secretaria Municipal de Saúde e os hospitais credenciados à rede suplementar de saúde. Como a equipe responsável pelo pré-natal não é a mesma que atende a parturiente, o pré-natal e o parto são oferecidos como se fossem serviços independentes, sem interlocução entre as equipes/serviços. Desta forma, percebemos que não existe vínculo entre a parturiente e a equipe que a atenderá no momento do parto.

As entrevistadas tinham preferência em relação ao tipo de parto, mas não decidiram o desfecho do parto. Em todos os casos, independente da preferência inicial, a decisão partiu da equipe de saúde, evidenciando a falta de protagonismo da mulher e reafirmando o médico como ator principal do parto. O parto institucionalizado, pautado em um modelo médico, coloca os aspectos científicos acima de outros, e, assim, o saber médico predomina sobre os desejos e necessidades da mulher (SANTOS et al., 2012).

Tal falta de protagonismo reforça a prática cultural de submissão ao saber médico. Com o avanço das técnicas assistenciais e dos equipamentos de saúde, a mulher foi destituída da apropriação do parto e de seu empoderamento, entregando essa responsabilidade em mãos alheias. Essa desvinculação da participação ativa no nascimento dos filhos pode estar relacionada ao fato de que as mulheres desconhecem seus direitos sexuais e reprodutivos, reforçando o discurso vigente de que a mulher deve ter um comportamento adequado, ficando calada, quieta e obedecendo à equipe médica (LOPES et al., 2009)

$\mathrm{O}$ fato de as mulheres não conhecerem seus direitos acarreta a perda de outros benefícios, como o direito a ter um acompanhante. A lei 11.108 (BRASIL, 2005) garan- te que a mulher tenha um acompanhante à sua escolha desde a internação até o momento do pós-parto. Mas o que pôde ser observado nas entrevistas foi que, mesmo depois de dez anos em que a lei foi sancionada, as parturientes algumas vezes ficavam sozinhas durante o processo de nascimento dos bebês, ou tinham limitações na escolha do acompanhante (como ser obrigatoriamente do sexo feminino, por exemplo).

A pesquisa de Brüggemann et al. (2015, p. 153) destacou que "a limitação da presença do acompanhante no cenário do nascimento, no Brasil, impossibilita que a mulher receba o apoio de sua rede social durante todo o processo parturitivo". Os enfermeiros entrevistados nessa pesquisa apontaram que a sala de cirurgia, em sua percepção, não é local adequado para o acompanhante, seja pela necessidade de assepsia, seja pelo fato de que o acompanhante muitas vezes não tem preparo emocional para presenciar o parto, sendo sua presença admitida nas salas de pré e pós-parto apenas. Muitas vezes, quando o profissional acredita que o parto ocorrerá sem complicações, a presença do acompanhante é facilitada. Os benefícios da presença de uma pessoa próxima à mulher são desconsiderados segundo esse estudo.

Outra contribuição da pesquisa de Brüggemann et al. (2015) foi a revelação de que, se o acompanhante não solicitar, não entra, e que, se solicita, é orientado a não entrar. Apenas em situações em que há insistência a sua entrada é permitida. Podemos inferir, assim, que apenas aqueles que conhecem a legislação e o demonstram poderiam acompanhar o parto. Segundo os autores:

Os obstáculos impostos pelos profissionais de saúde, para o cumprimento integral da Lei do Acompanhante, são pautados por ideias pré-concebidas de que o ambiente hospitalar não é lugar para o acompanhante e que a sua presença pode interferir negativamente na organização do processo de trabalho (BRÜGGEMANN et al., 2015, p. 157).

O acompanhante não é uma pessoa que pretende apenas ver o bebê nascer. A presença do acompanhante, além de proporcionar apoio emocional à mulher, também garante uma pessoa a auxiliando nas tomadas de decisões durante o trabalho de parto e verificando junto à equipe de saúde sobre a real necessidade dos procedimentos adotados (DODOU et al., 2014).

Para tanto, algumas medidas precisam ser tomadas, como por exemplo a inserção do acompanhante desde o princípio da gestação (pré-natal) para que possa ter conhecimento de todo processo e de fato contribuir com a gestante no momento do parto. Outra medida seria a adequação do ambiente para que a mulher pudesse ter o acompanhante à sua escolha, independente do gênero do mesmo (DODOU et al,. 2014).

Nas entrevistas, vimos que nem todas as mulheres tiveram contato imediato com o bebê após o nascimento. Esse contato tem ligação direta com o tipo de parto: em partos via vaginal, o contato era imediato; em cesáreas, o contato com o bebê acontecia apenas quando a mulher saía do centro cirúrgico. A realização de procedimentos no recém-nascido (como limpar, aspirar, avaliar, dar ba- 
nho e outros) pode acarretar o retardamento do contato precoce entre mãe e filho. Na cesariana, principalmente quando realizada fora do trabalho de parto, o estado de alerta do bebê é menor. Esse fator, associado à sonolência da mãe em decorrência da analgesia, pode também dificultar o contato pele a pele entre a díade. O contato precoce com o bebê é importante para o sucesso de certos processos fisiológicos como a dequitação da placenta, a diminuição do sangramento da mãe, a estimulação da produção de leite e o estabelecimento da amamentação (SALGADO; NIY; DINIZ, 2013).

A violência no tratamento à mulher no momento do parto (não poder escolher a posição mais confortável, ser alvo de deboche, ouvir piadas em momento de dor e ansiedade), traduzida por desrespeito e maus-tratos, também esteve presente no estudo de RODRIGUES et al. (2015), o que se encontra em desalinho com as propostas da Política Nacional de Humanização.

Por fim, vale destacar a necessidade de estudos e medidas a respeito do parto e do nascimento no Brasil. Segundo Weidle et al. (2014, p. 52), "a humanização do parto passa não apenas por medidas governamentais, que assegurem legalmente os direitos das gestantes, mas perpassa também o comportamento e o comprometimento dos profissionais responsáveis" pelo cuidado à mulher e bebê nesta etapa de vida. Essa importante consideração nos leva a destacar a necessidade de implementação de ações voltadas para a Educação Permanente em Saúde (BRASIL, 2009).

\section{Considerações finais}

O trabalho buscou compreender como as parturientes da rede pública de saúde vivenciaram o nascimento de seus filhos. As falas das mulheres evidenciaram aspectos urgentes a serem revistos na atenção ao parto, como a falta de vínculo entre a mulher e a equipe de saúde, a falta de protagonismo da mulher e as restrições em relação ao acompanhante. Analisar as narrativas do trabalho de parto e parto contribuiu para a compreensão do significado atribuído a esse momento pelas parturientes. Refletir sobre a percepção de cada mulher auxilia na escolha de estratégias de cuidado que possam atender a mulher no momento do nascimento de seu bebê.

\section{Informações sobre as autoras:}

Carolina Lemes Valadão

(iD) https://orcid.org/0000-0003-4024-0255

(9) http://lattes.cnpq.br/6787001647445142

Graduada em Psicologia pela Universidade Federal de Uberlândia (UFU) e Mestre pela mesma universidade. Pesquisa a Relação Família-Escola e as possíveis contribuições da Psicologia Escolar nessa relação. Já atuou como psicóloga na educação infantil e atualmente trabalha na coordenação do ensino fundamental anos finais em uma escola da rede privada de ensino. É mãe de três filhos.

Renata Fabiana Pegoraro

(iD) https://orcid.org/0000-0001-6052-5763

(9) http://lattes.cnpq.br/4823645280355146

Renata Fabiana Pegoraro é docente do Instituto de Psicologia da Universidade Federal de Uberlândia. Atua como professora permanente do Mestrado em Psicologia do IP-UFU. Possui graduação em Psicologia pela Universidade de São Paulo - Campus Ribeirão Preto (1996), especialização em Saúde Coletiva pela Universidade Federal de São Carlos, mestrado em Psicologia pela Universidade de São Paulo (2002) e doutorado em Psicologia pela Universidade de São Paulo (2007). Concursada junto à UFU desde 2014, desenvolve atividades de ensino, pesquisa e extensão na área da saúde/saúde mental. Desenvolve pesquisas na área de Psicologia e Políticas Públicas de saúde/saúde mental.

\section{Contribuições das autoras:}

Ambas as autoras colaboraram ao longo do processo, desde a elaboração até a revisão final do manuscrito. As autoras aprovaram o manuscrito final para publicação.

\section{Como citar este artigo:}

\section{ABNT}

VALADÃO, Carolina Lemes; PEGORARO, Renata Fabiana. Vivências de mulheres sobre o parto. Fractal: Revista de Psicologia, Niterói, v. 32, n. 1, p. 91-98, jan./abr. 2020. https://doi. org/10.22409/1984-0292/v32i1/5739

\section{APA}

Valadão, C. L., \& Pegoraro, R. F. (2020, Janeiro/Abril). Vivências de mulheres sobre o parto. Fractal: Revista de Psicologia, 32(1), 91-98. doi: https://doi.org/10.22409/1984-0292/v32i1/5739

\section{Referências}

AGUIAR, Janaína Marques de; D’OLIVEIRA, Ana Flávia Pires Lucas. Violência institucional em maternidades públicas sob a ótica das usuárias. Interface: Comunicação, Saúde, Educação, Botucatu, v. 15, n. 36, p. 79-92, 2011. https://doi. org/10.1590/S1414-32832010005000035

ALEIXO, Caroline. Índices de cesáreas ainda é alto na rede pública de Uberlândia. Disponível em: https://g1.globo.com/ minas-gerais/triangulo-mineiro/noticia/indice-de-cesariasainda-e-alto-na-rede-publica-de-uberlandia.ghtml. Acesso em: 18 fev. 2020.

AMORIM, Melania. A retomada do protagonismo feminino no Parto. Entrevista concedida à Graziela Wolfart. Domtotal, 30 dez. 2012. Disponível em: https://domtotal.com/ periscopio/1613/2012/12/a-retomada-do-protagonismofeminino-no-parto. Acesso em: 18 nov. 2018.

BARDIN, Laurence. Análise de conteúdo. Lisboa: Edições 70, 1977.

BRASIL. Lei $n^{\circ} 11.108$, de 7 de abril de 2005. Dispõe sobre a garantia das parturientes ao direito à presença de um acompanhante durante o trabalho de parto, parto e pósparto imediato, no âmbito do Sistema Único de Saúde/ SUS. Disponível em: http://www.planalto.gov.br/ccivil_03/ Ato2004-2006/2005/Lei/L11108.htm. Acesso em: 26 jun. 2015.

BRASIL. Lei $n^{\circ} 11.634$ de 27 de dezembro de 2007. Dispõe sobre o direito da gestante ao conhecimento e à vinculação à maternidade onde receberá assistência no âmbito do Sistema Único de Saúde/SUS. Disponível em: http://www.planalto.gov. br/ccivil_03/_Ato2007-2010/2007/Lei/L11634.htm. Acesso em: 26 jun. 2015 .

BRASIL. Ministério da Saúde. Pré-natal e puerpério: atenção qualificada e humanizada. 3 ed. Brasília: MS, 2008.

BRASIL. Ministério da Saúde. Política Nacional de Educação Permanente em Saúde. Secretaria de Gestão do Trabalho e da Educação na Saúde. Departamento de Gestão da Educação em Saúde. Brasília: MS, 2009. 
BRASIL. Ministério da Saúde. Política nacional de atenção integral à saúde da mulher: princípios e diretrizes. Brasília: MS, 2011.

BRASIL. Ministério da Saúde. Humanização do parto e nascimento. Brasília: MS, 2014.

BRÜGGEMANN, Odaléa Maria et al. M. No parto vaginal e na cesariana acompanhante não entra: discursos de enfermeiras e diretores técnicos. Revista Gaúcha de Enfermagem, Porto Alegre, v. 36, n. spe, p. 152-158, 2015. https://doi. org/10.1590/1983-1447.2015.esp.53019

DINIZ, Simone Grilo; CHACHAM, Alessandra. Dossiê humanização do parto. São Paulo. Ed. Rede Feminista de Saúde, 2002. Disponível em: https://www.researchgate.net/ publication/304346717 Dossie Humanizacao do Parto. Acesso em: 18 fev. 2020.

DODOU, Hilana Dayana et al. A contribuição do acompanhante para a humanização do parto e nascimento: percepção das puérperas. Escola Anna Nery, Revista de Enfermagem, Rio de Janeiro, v. 18, n. 2, p. 262-269, abr./jun. 2014. https://doi. org/10.5935/1414-8145.20140038

DOMINGUES, Rosa Maria Soares Madeira; SANTOS, Elizabeth Moreira dos; LEAL, Maria do Carmo. Aspectos da satisfação das mulheres com a assistência ao parto: contribuição para o debate. Cadernos de Saúde Pública [online], Rio de Janeiro, v. 20, suppl. 1, p. S52-S62, 2004. https://doi. org/10.1590/S0102-311X2004000700006

DUARTE, Rosália. Entrevistas em pesquisas qualitativas. Educar em Revista, Curitiba, n. 24, p. 213-225, jul./dez., 2004. https://doi.org/10.1590/0104-4060.357

GOMES, Annatália Meneses de Amorim; NATIONS, Marilyn K.; LUZ, Madel Therezinha. Pisada como pano de chão: experiência de violência hospitalar no Nordeste Brasileiro. Saúde e Sociedade, São Paulo, v. 17, n. 1, p. 61-72, jan./mar., 2008. https://doi.org/10.1590/S0104-12902008000100006

LEAL, Maria do Carmo; GAMA, Silvana Granado Nogueira da. Sumário executivo temático da pesquisa. In: LEAL, Maria do Carmo (Org.). Nascer no Brasil. Rio de Janeiro: Fiocruz, 2014. p. 2-7. Disponível em: http://www.ensp.fiocruz.br/portalensp/informe/site/arquivos/anexos/nascerweb.pdf. Acesso em: 9 nov. 2016.

LOPES, Caroline Vasconcelos et al. Experiências vivenciadas pela mulher no momento do parto e do nascimento do filho. Cogitare Enfermagem, v. 14, n. 3, p. 484-490, jul.-set. 2009. Disponível em: https://revistas.ufpr.br/cogitare/article/ viewFile/16178/10697. Acesso em: 18 fev. 2020.

OLIVEIRA, Andressa Suelly Saturnino de Oliveira et al. Percepção das mulheres sobre a vivência do trabalho de parto e parto. Revista Rene, Fortaleza, v. 11, p. 32-41, 2010. Disponível em: http://periodicos.ufc.br/rene/article/view/4655. Acesso em: 12 ago. 2019.

OLIVEIRA, Sonia Maria Junqueira Vasconcelos de et al. Tipo de parto: expectativa das mulheres. Revista Latino Americana de Enfermagem, Ribeirão Preto, v. 10, n. 5, p. 667-674, 2002. https://doi.org/10.1590/S0104-11692002000500007

RODRIGUES, Diego Pereira et al. A peregrinação no período reprodutivo: uma violência no campo obstétrico. Escola Anna Nery, v. 19, n. 4, p. 614-620, out./dez. 2015. Disponível em: $\quad$ http://www.scielo.br/pdf/ean/v19n4/1414-8145ean-19-04-0614.pdf. Acesso em: 13 abr. 2019.
SALGADO, Heloísa de Oliveira; NIY, Denise Yoshie; DINIZ, Carmen Simone Grilo. Meio grogue e com as mãos amarradas: o primeiro contato com o recém-nascido segundo mulheres que passaram por uma cesárea indesejada. Journal of Human Growth and Development, São Paulo, v. 23, n. 2, p. 190-197, mai.-ago. 2013. Disponível em: http://pepsic.bvsalud.org/pdf/ rbcdh/v23n2/pt_11.pdf. Acesso em: 17 jun. 2018.

SANTOS, Luciano Marques et al. Atenção no processo parturitivo sob o olhar da puérpera. Revista de Pesquisa Cuidado é Fundamental [online], Rio de Janeiro, v. 4, n. 3, p. 2655-2666, jul.-set. 2012. Disponível em: https://www.redalyc. org/articulo.oa? id=505750894005. Acesso em: 23 out. 2019.

WEIDLE, Welder Geison et al. Escolha da via de parto pela mulher: autonomia ou indução? Cadernos de Saúde Coletiva, Rio de Janeiro, v. 22, n. 1, p. 46-53, 2014. https://doi. org/10.1590/1414-462X201400010008 